A rising tide

The ice covering

Greenland holds

enough water to raise

the oceans seven

metres - and it's

starting to melt. How

far will it go? Quirin

Schiermeier wades into the evidence.

$\mathrm{G}$ reenland was not always covered with ice. About 60 million years ago, when Earth's climate was much warmer than today, the world's largest island was a grassy arctic tundra across which the ancestors of modern horses and other mammals migrated.

Since that time, millions of cubic kilometres of ice have accumulated on the island. No longer home to migrating beasts, Greenland now serves as a reservoir for immense quantities of water. And it would be best for the water to stay there. If Greenland's ice sheet were to melt, the oceans would rise by seven metres, enough to cover large parts of low-lying countries such as Bangladesh and the Netherlands. New York cabbies would have to buy motor boats. Most of southern Florida, from Key West to the Everglades, would sink beneath the waves.

This scenario is not just fantasy. It has become clear in recent years that climate warming is beginning to trigger rapid and substantial changes in the polar ice caps. In Greenland, these changes may be irreversible. New research suggests that if Greenland's ice sheet melts, it will probably not form again, even if temperatures and heattrapping greenhouse gases returned to preindustrial levels.

Although the Greenland ice sheet is much smaller than its counterpart in Antarctica, where some ice loss has also been noted, it now seems more likely to contribute to a rise in sea level. For one thing, floating sea ice has been on the decline in the north in recent years. With less ice around to reflect sunlight, the oceans are absorbing more energy than they were before, leading to further warming. In contrast, southern sea ice has been relatively stable. The lower average temperature in Antarctica means that ice melting off glaciers refreezes before it can reach the sea. But Greenland's warmer summers allow glacial melt to pour into the North Atlantic, further accelerating the loss of ice.

The bulk of Greenland's ice, more than

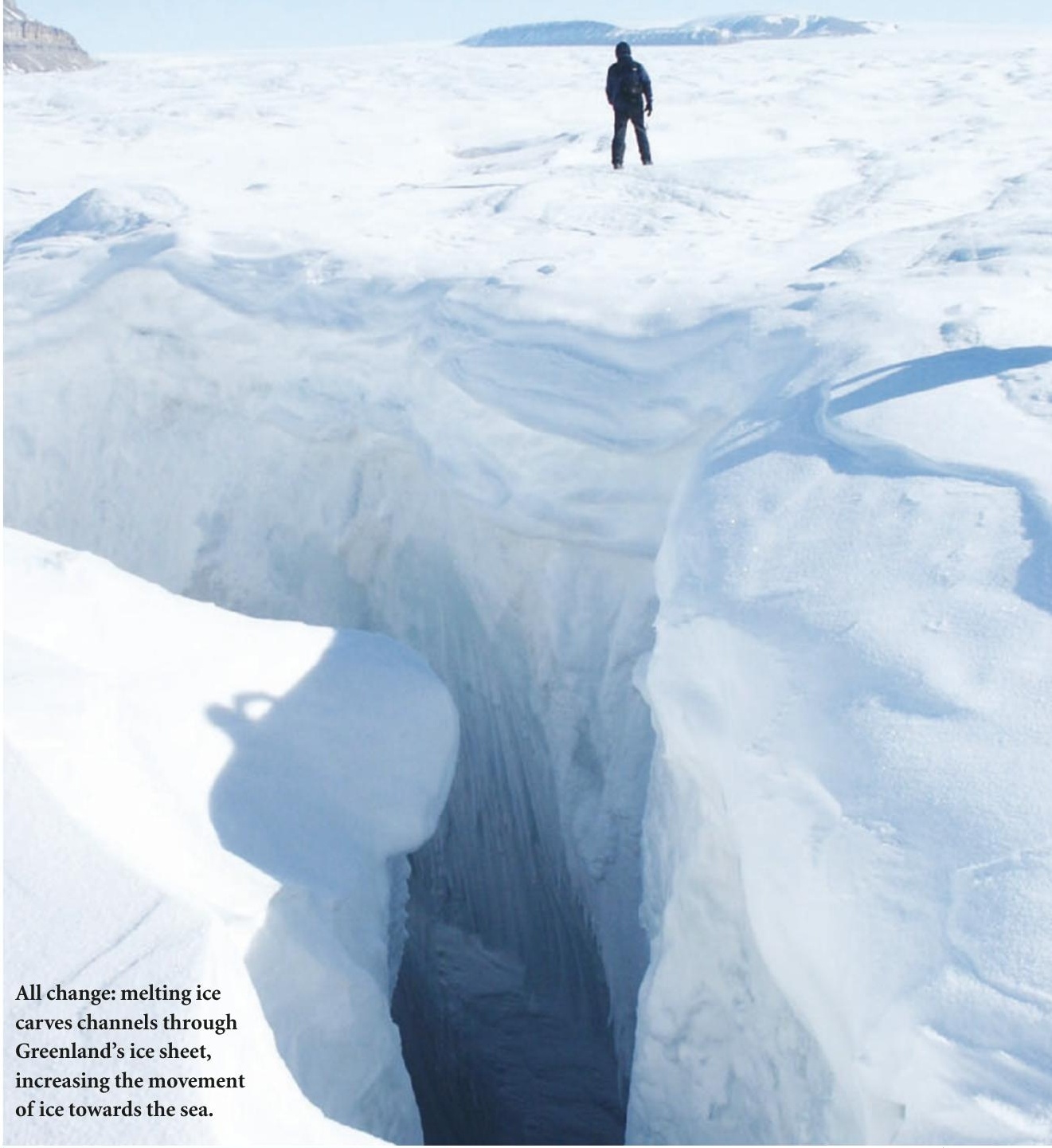

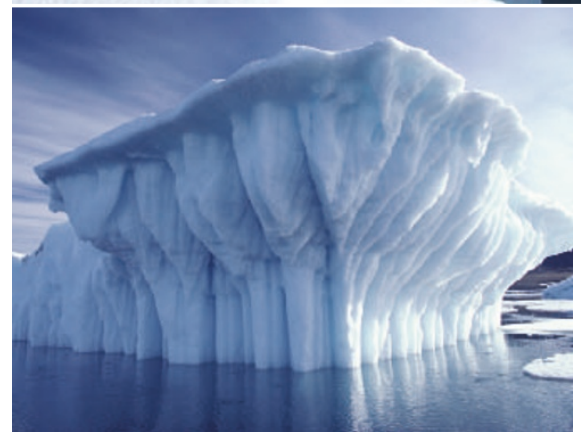

3,000 metres thick in the centre, is a remnant of the last ice age, which peaked some 20,000 years ago. It still exists because temperatures in the Holocene - the period from the end of the last glacial epoch to the present - have never risen beyond a point where the ice lost to melting, evaporation and the march of glaciers to the sea has on average exceeded the accumulation of new ice through snowfall. The ice sheet has been in balance.

\section{Slippery slope}

But there is growing evidence that the system is about to lose its equilibrium. Philippe Huybrechts, a glaciologist and ice-sheet modeller at the Free University in Brussels, has modelled the behaviour of Greenland's ice sheet under various climate scenarios. According to projections, Greenland's mean annual temperature could increase by $8{ }^{\circ} \mathrm{C}$ by 2100 . Huybrechts found that this would mean that by the end of the millennium, the ice sheet would shrink to a small glaciated area far inland and the sea level would rise by six metres. This is a worst-case scenario, says Huybrechts, who reported his findings in the third assessment report of the Intergovernmental Panel on Climate Change (IPCC), but it is not outside the realms of possibility. Substantial shrinking can be expected even for more conservative temperature rises, Huybrechts says ${ }^{1}$.

Because a certain amount of global warming now seems inevitable in response to greenhouse gases already released through human activity, an important question is whether Greenland's ice sheet, which has already begun to disintegrate, will reach a point beyond which it cannot recover.

One body of work suggests that it may. Because the ice is so thick, much of Greenland's heartland lies at a very high altitude. This, in turn, ensures sufficient annual snowfall to build up new ice as fast as the sheet degrades near the coast. But modelling by Jonathan Gregory, a climate researcher at the Centre for Global Atmospheric Modelling in Reading, UK, suggests that as ice is lost, portions of the surface of Greenland's interior will end up at lower elevations where the air is warmer. Less snowfall and more rain would cause the ice to disappear at a 


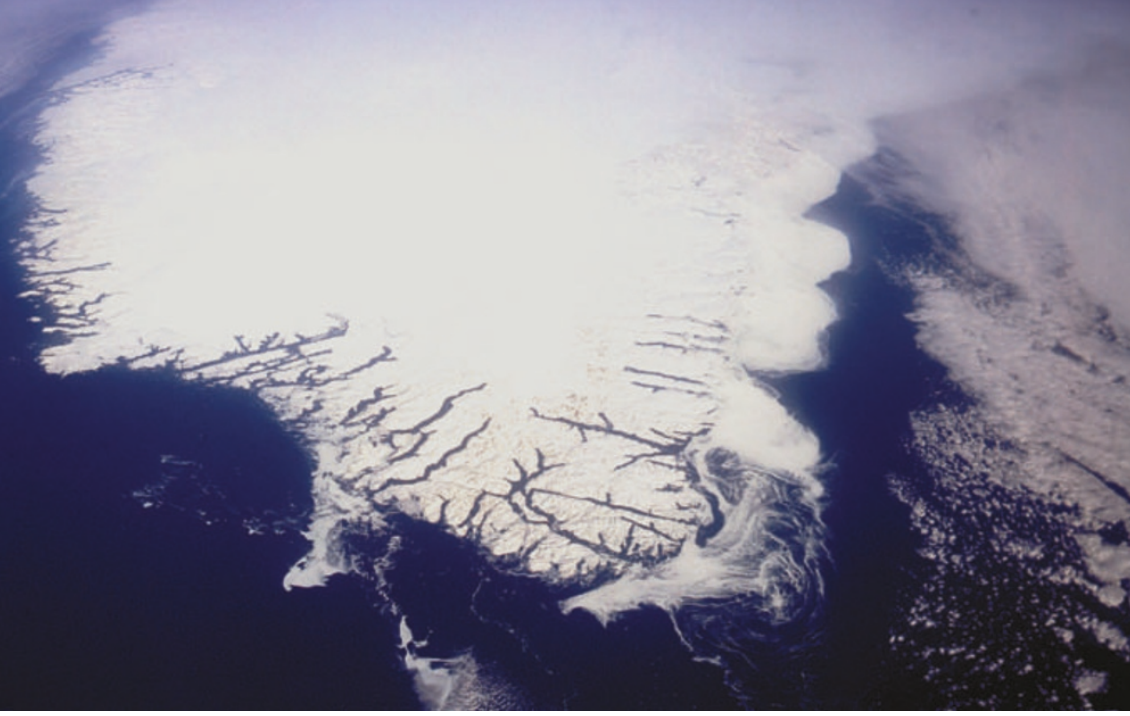

Hotting up: the temperature on Greenland looks set to rise by some $3^{\circ} \mathrm{C}$ by the end of this century.

faster rate than it was being replaced, leading in turn to further drops in elevation.

In one simulation carried out at the Hadley Centre for Climate Prediction and Research in Bracknell, UK, Gregory and his team modelled the topography of Greenland after completely removing the ice sheet. They then simulated cool pre-industrial climate conditions - which would easily maintain the existing ice sheet - to see whether the ice would regenerate. It did not ${ }^{2}$. The ice sheet, they concluded, creates its own local climate. It depends on itself to exist.

"The ice is only there because it has always been there since the end of the last ice age," agrees Huybrechts. "If it had melted at some point in the past 15,000 years it would not have come back."

\section{Losing out}

Meanwhile, satellite and aircraft surveys as well as measurements by scientists on the ground are painting a picture of an ice sheet that is rapidly losing mass. Although data for some regions are still poor, it is clear that most of the loss is taking place near the coasts ${ }^{3}$.

Bill Krabill, a project scientist at NASA's Goddard Space Flight Center in Wallops Island, Virginia, coordinated aerial surveys of the ice sheet's elevation from 1994 to 1999. Aircraft flying at a steady altitude aimed a laser at the surface and calculated the height of the ice based on the time it took for the laser beam to bounce back. As ice is lost from the edges first, Greenland's ice sheet, a shallow dome, is effectively getting steeper. Krabill's team found that over five years, ice around the edges disappeared faster than before ${ }^{4}$. Subsequent measurements have continued to support that conclusion, Krabill says.

One reason the pace may be accelerating is that the melted ice does more than just run into the ocean. It also seeps down to the ice-bedrock interface, where it acts as a lubricant, quickening the pace of ice movement towards the sea. As the glaciers reach the margins of the island, great icebergs split off into the water.

"Along the coasts, all the glaciers but one are thinning like mad, and they're also flowing faster than they ought to," says Eric Rignot, a glaciologist and principal scientist at the Jet Propulsion Laboratory in Pasadena, California.

Scientists are less certain about what is going on in the central area of the ice sheet. Is

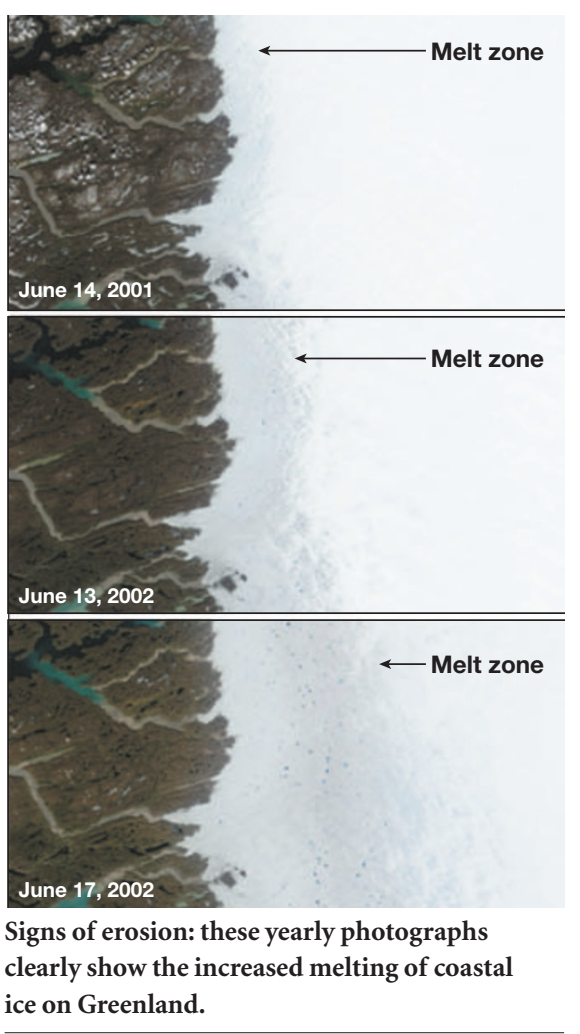

it getting thicker or thinner? The key will be to find out whether the changes near the edges are just normal fluctuations or the beginning of a long-term trend, says Rignot. "Changes initiated in coastal regions will propagate inland very quickly," he believes.

Krabill estimates the rate of ice loss from Greenland to be about 50 cubic kilometres per year, or roughly $1 / 50,000$ of its total volume. That should produce enough water to raise the global sea level by an average of 0.13 millimetres per year ${ }^{5}$. This is not yet an acute threat, says Krabill, but he notes that his estimation of net mass loss is conservative. "It could easily be twice that much,” he says.

\section{Heated debate}

A number of factors complicate forecasts about the ice sheet's future. Computer models suggest that if Greenland warms up by $3{ }^{\circ} \mathrm{C}$ in the next 100 years - which is well within the projections of the IPCC the ice sheet cannot survive ${ }^{6}$. But these models depend on assumptions about the likely rate of ice retreat that are not guaranteed to be correct, in part because the flow dynamics of glaciers are not yet fully understood. In Antarctica, for example, ice streams seem to come and go, and the movement of glaciers has been seen to speed up and slow down very quickly. But the cause of such shifts is not always clear.

Further complicating the models are the contradictory effects a warmer climate may have on polar ice sheets. As temperatures rise, evaporation from the surrounding oceans will increase, sending more moisture inland. This will increase snowfall over high-elevation accumulation zones. On the other hand, the simultaneous increase in summer rains could accelerate the melting. So the net effect of increased precipitation is hard to predict.

One final uncertainty is the fate of the Gulf Stream, which delivers warm tropical water to the North Atlantic and keeps Europe much warmer than it would otherwise be. Some scientists believe that the Gulf Stream is weakening in response to the massive influx of fresh water from shrinking glaciers. If it became weak enough, they say, Greenland would chill down again and its ice sheet might stabilize.

Fresh water is stored as ice all over the world, not just in ice sheets but also on inland mountain peaks. In theory, if all of it melted, the oceans would rise an astounding 80 metres. Fortunately, climate experts agree that this is not on the cards. But the uncertainty over Greenland is just one more reason not to put off that vacation to Florida.

Quirin Schiermeier is Nature's German correspondent.

1. Huybrechts, P. \& de Wolde, J. J. Clim. 12, 2169-2188 (1999).

2. Toniazzo, T., Gregory, J. M. \& Huybrechts, P. J. Clim. 17, 21-33 (2004)

Rignot, E. \& Thomas, R. H. Science 297, 1502-1506 (2002).

4. Zwally, H. J. et al. Science 297, 218-222 (2002).

5. Krabill, W. et al. Science 289, 428-430 (2000).

6. Huybrechts, P., Letreguilly, A. \& Reeh, N. Glob. Planet. Change 3, 399-412 (1991). 